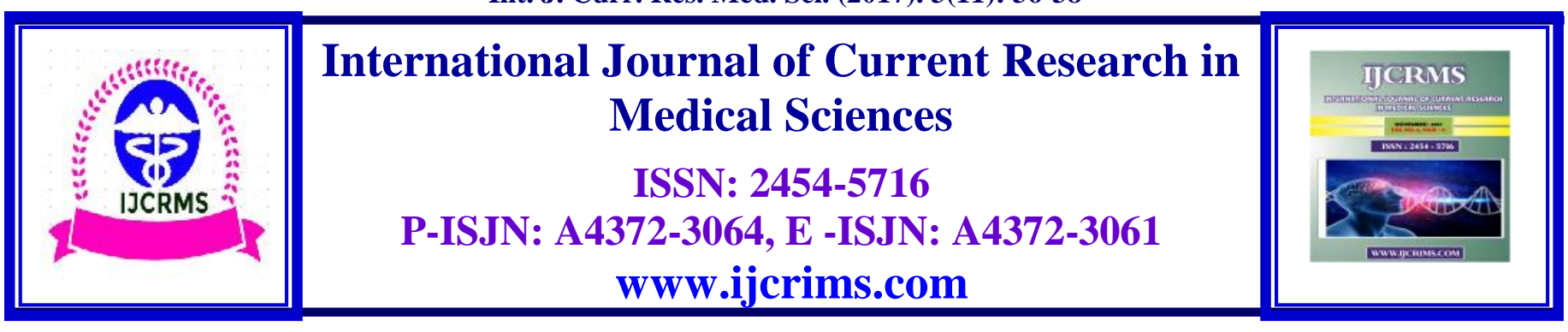

\title{
PICA - A Rare case of Eating Raw rice
}

\author{
Dr Sajeesh. S ${ }^{1}$, Dr. S. Arun ${ }^{2}$, Dr. R. Kumar ${ }^{3}$ and Dr. Vishnu G Ashok ${ }^{4}$ \\ ${ }^{1}$ Final Year Post graduate, Department of Psychiatry, \\ Sri Manakulavinayagar Medical College and Hospital, Puducherry \\ ${ }^{2}$ Associate Professor, Department of Psychiatry, \\ Sri Manakulavinayagar Medical College and Hospital, Puducherry \\ ${ }^{3}$ Professor \& Head, Department of Psychiatry, \\ Sri Manakulavinayagar Medical College and Hospital, Puducherry \\ ${ }^{4}$ Corresponding Author: Dr.Vishnu G Ashok, \\ Assistant Professor, Department of Community Medicine, \\ Sree Mookambika Institiute of Medical Sciences, Kulasekharam, Tamilnadu
}

\begin{abstract}
PICA is an act or habit of eating non-edible items such as stone, bricks, chalk, soap, paper, soil etc . The causes of pica suggests that the disorder is a specific appetite caused by mineral deficiency in many cases, typically iron deficiency. It can occurs in males and females. More common among children with autism spectrum disorder and intellectual disability. We report a case of pica in an adult female.
\end{abstract}

Keywords: Pica, Iron deficiency, Anaemia

\section{Introduction}

PICA is an act or habit of eating non-edible items such as stone, bricks, chalk, soap, paper, soil etc. it is only identified only when medical problems such as intestinal obstruction, intestinal infections or poisonings arise such as lead poisoning. Pica can emerge in young children, adolescents or adults, minimum of 2 years of age is suggested by Diagnostic and statistical manual of mental disorders. It can occurs in males and females. More common among children with autism spectrum disorder and intellectual disability. The true incidence of pica is not known but it is estimated to be $75 \%$ in infants, $15 \%$ in two-three year old toddlers and $10-33 \%$ among the institutionalized mentally retarded children. ${ }^{1,2}$

\section{Case Report}

A 20-year old unmarried female patient who reported to the psychiatric department with recurrent abdominal pain, tiredness since 2 days. Medical history revealed chronic abdominal pain since 5 years. On general physical examination patient was mildly anaemic with pallor and well oriented and conscious .On abdominal examination it was soft and non tender. On further 
explicit questioning about particular eating habits, the patient reluctantly disclosed an almost daily consumption of "raw rice" over more than 9 years. She reported having developed a particularly strong craving for raw rice, in which she used to eat it daily while studying or even at the class or outside. She had acquired this habit when she was studying in $9^{\text {th }}$ standard .used to carry a box of raw rice to the school without her parents knowing. Patient explained that since past 5 years she had been aware of her problem of ingestions and also it has increased with thoughts and images of rice. She reported that it is not normal to ingest raw rice but with time her frequency of thoughts and desire to ingest raw rice has increased. She was aware that ingestions were related to her increasing images and thoughts of raw rice and eating it longingly. The thoughts were frequent and last for minutes and with time it was increasing. Those thoughts and images were strong, destructive and intrusive, even when she tries to resist or control herself she fails and give up trying and forcefully coupled to go to the kitchen and ingests the raw rice (around 250 grams /day). After getting relief from intrusive thoughts, she would stop ingestion .She would tries to hide herself from her parents for any confrontation. On routine blood investigation her haemoglobin was $10 \mathrm{gm} \%$. The patient was investigated for serum iron, serum zinc, stool and urine test. We noticed significant reduction in serum ferritin, calcium and zinc levels indicating iron and zinc deficiency. This led to a diagnosis of pica.PA chest X-ray was normal with no other gastrointestinal abnormality on endoscopy and USG abdomen was normal. Thus proper history remained the most inexpensive investigation in this case.

\section{Discussion}

The word pica comes from the Latin word for magpie, a bird known for its unusual eating habits. Pica is characterized by persistent craving and compulsive eating of non-food substances. This has been reported as early as 40 B.C and addressed in medical books as far back in $1563 .^{3}$ The research that has been done on the causes of pica suggests that the disorder is a specific appetite caused by mineral deficiency in many cases, typically iron deficiency, which sometimes is a result of celiac disease often the substance eaten by someone with pica contains the mineral in which that individual is deficient. However, it is unclear whether pica causes or is the consequence of iron deficiency anemia. Second, adsorption of $\mathrm{Fe}^{2+}$ and $\mathrm{Fe}^{3+}$ to large active surface area of calcium carbonate may lead to a reduction of available iron in the duodenum. As a consequence the absorption of iron might decrease, resulting in iron deficiency. ${ }^{4}$ Third, traces of magnesium silicate commonly found in chalk may cause abrasion and favor increased mucosal sloughing and iron loss. Fourth, geophagia may cause parasitic infestation and iron deficiency. Pica is currently recognized as a mental disorder. Mental health conditions such as obsessive-compulsive disorder (OCD) and schizophrenia can sometimes cause pica. It is suggested that stress associated with traumatic events is linked to pica disorder such as maternal deprivation, parental separation or neglect, child abuse, disorganized family structure and poor parent-child interaction. ${ }^{5}$ Pica may be secondary to hookworm infection with symptoms like bluish hue of the skin, particularly around the mouth which was absent in our case. Treatment for pica varies based on the patient's category (e.g. child, developmentally disabled, pregnant or psychopathic) and may emphasize psychosocial, environmental and family guidance approaches. An initial approach often involves screening for and if necessary treating any mineral deficiencies. In the management of Pica of psychotic etiology, therapy and medication such as (SSRIs) selective serotonin reuptake inhibitors have been used successfully. ${ }^{6,7}$ In the present case patient was educated about the condition referred for psychological counseling and advised to listen music, practice meditation and yoga. Some medications may be helpful in reducing the abnormal eating behavior if pica occurs in the course of a developmental disorder, such as mental retardation or pervasive developmental disorder. They enhance dopaminergic functioning, which is believed to be associated with the occurrence of pica. 
Differential diagnosis: Iron and zinc deficiencies, Avoidance of food, Obsessive compulsive disorder

\section{Conclusion}

Although pica is a rare condition, in day to day practice it may be underestimated. Children between the ages of 2 and 20 years of age have been known to have pica. Therefore it is important to remember and enquire about particular eating habits. Thus, proper history remains the most inexpensive investigation.

\section{References}

1. Crosby WH. Pica. JAMA. 1976 Jun 21; 235(25):2765

2. Parry-Jones B, Parry-Jones WL. Pica: symptom or eating disorder? A historical assessment. The British Journal of Psychiatry. 1992 Mar 1; 160(3):341-54
3. Hergüner S, Özyıldırım , Tanıdır C. Is Pica an eating disorder or an obsessive-compulsive spectrum disorder?. Progress in NeuroPsychopharmacology and Biological Psychiatry. 2008 Dec 12; 32(8):2010-1.

4. Von Garnier C, Stünitz H, Decker M, Battegay E, Zeller A. Pica and refractory iron deficiency anaemia: a case report. Journal of Medical Case Reports. 2008 Oct 6; 2(1):324

5. Rose EA, Porcerelli JH, Neale AV. Pica: common but commonly missed. The Journal of the American Board of Family Practice. 2000 Sep 1; 13(5):353-8.

6. Bryant-Waugh R, Markham L, Kreipe RE, Walsh BT. Feeding and eating disorders in childhood. International Journal of Eating Disorders. 2010 Mar 1; 43(2):98-111.

7. Swamy N, Dewang D. Pica disorder (Geophagia): a case report. International Journal of Dental Clinics. 2011 Dec 4; 3(4).

\begin{tabular}{|c|l|}
\hline \multicolumn{2}{|c|}{ Access this Article in Online } \\
\hline & Website: \\
\hline Quick Response Code & www.ijcrims.com \\
\hline
\end{tabular}

How to cite this article:

Sajeesh. S, S. Arun, R. Kumar and Vishnu G Ashok. (2017). PICA - A Rare case of Eating Raw rice. Int. J. Curr. Res. Med. Sci. 3(11): 36-38.

DOI: http://dx.doi.org/10.22192/ijcrms.2017.03.11.008 